\title{
Spor ile Siyasetin İlişkisi Üzerine Bir Analiz; Sporu Siyasete Alet Etmek
}

\author{
Mustafa İnce*
}

Karabük Üniversitesi, Safranbolu Meslek Yüksekokulu, Karabük

\begin{abstract}
$\ddot{O} z$
Fiziksel, sosyal, ekonomik vb. birçok farklı boyutu bulunan sporun siyasetle ilişkisi her zaman tartışma konusu olmuştur. Büyük kitlelerin ilgilediği spor, kitlelerin yönetimine talip olan siyasiler tarafindan çeşitli şekillerde siyasetin içine çekilmek istenmiştir. Siyasetçiler bu şekilde, spordan siyasi bir kazanç elde etmeyi amaçlamışlardır. Hem sporun (özellikle de futbolun) hem de siyasetin ortak paydası olan kitleleri etkilemek için, spor olaylarının olumlu yönlerinden faydalanmak isteyen siyasiler, bunda kimi zaman başarll olmuş, kimi zaman da tepki görmüşlerdir. Peki, spor siyasetin neresindedir ya da neresinde olmalıdır? Çalı̧̧mada sporun siyasetle olan ilişkisinin irdelenmesi amaçlanmaktadır. Tarihsel süreçte gelişen spor olaylarn ile siyasi bağlantılar incelenerek, spor ve siyasetin ilişkisinin boyutları ele alınmıştır.
\end{abstract}

Anahtar Kelimeler: Spor ve Siyaset, Analiz, İlişki, Sporu Alet Etmek

\section{An Analysis on Relation of Sport and Politics; Play Politics With Something}

\begin{abstract}
Relation of politics and sport that has many different aspects such as physical, social, economic etc. has been always become a matter of debate. Sport that is interested in mass, wanted to be counted in the politics by politicians with different ways. In this way, politicians have been wanted to gain political profit via the sport. To effect mass, who are common ground of both sport (specially football) and politics, politicians who want to take advantage of positive sides of the sport have sometimes succeded, but sometimes got reactions as well. Well, where is the sport in the politics or where it should be? In this study, it has been aimed to examine relation between sport and politics. Sports events in historical process and relation between sport and politics have been discussed from varios aspects
\end{abstract}

Keywords: Sport and politics, analysis, relation of politics and sport.

\section{GíRiş}

McLuhan'ın da belirttiği gibi, (Yaylagül, 2010: 69) kitle iletişim araçları sayesinde dünyanın küresel bir köye dönüştüğü günümüzde, insanlar, dünyanın herhangi bir yerinde gerçekleşen bir etkinliğe anında erişme imkânı bulabilmektedirler. Bu sayede spor ve spor olayları geniş halk kitleleri tarafından izlenmekte, takip edilmekte ve uygulanmaktadır. Bunun sonucunda da spor bir yaşam biçimine dönüşmekte ve halkın tüm kesimleri çeşitli şekillerde spor olaylarının içine çekilmektedir. Bununla birlikte kitlelerin spora olan bu ilgisini değerlendirmek isteyen, ekonomik ve sosyal olarak çıkara dönüştürmeyi arzu eden bir kesim de ortaya çıkmıştır. Spor, kitle iletişim araçlarının da desteğiyle ekonomik açıdan oldukça kazançlı bir pazarlama aracı olmuş, ticarete dâhil edilmiş, adeta endüstrileşmiştir. Ekonomi çevrelerinin ticari bir meta haline getirdiği sporu, siyasiler de kendi amaçlarına hizmet eden bir olgu haline getirmeyi istemiş, bunu gerçekleştirmek için yoğun çaba harcamışlardır. 
Siyasiler, spora -özellikle büyük kitlelerin ilgilendiği dallarına- ilgi göstermiş, destek olmuş, sahiplenmiş ve hatta bu alanlarda başarı sağlanması için gayret göstermişlerdir. Bugün başta kulüp yöneticileri, ticari işletmeler, reklamcılar, siyasetçiler ve medya olmak üzere sporun nimetlerinden faydalanan farklı gruplar ortaya çıkmıştır. Özellikle siyasiler tarihin hemen her döneminde sporun destekçisi konumunda bulunarak, elde edilen/edilecek başarılardan kendilerine pay çıkarmayı ummuşlardır.

$\mathrm{Bu}$ çalışmada, sporun, özellikle de futbolun siyasi iktidarlarla olan ilişkileri tarihsel bağlamda ele alınarak sporun siyasetle ilişkisi irdelenmiştir.

\section{Sporun Gelişimi ve Özellikleri}

İnsanların ferdi veya toplu olarak fiziki, ruhi ve düşünme kabiliyetini, kendine ve bir rakibine karşı, önceden belirlenmiş bir düzen içinde başarı kazanmaya yönelik ve mücadele heyecanını yaşamak için yaptığı beden hareketlerinin bütününe verilen genel isim olarak açıklanabilen sporun, çok eski zamanlardan beri gerek ferdi, gerekse toplu olarak yapıldığı bilinmektedir (Çevrimiçi, 2014, 10 Mart).

Latince kökenli olan spor sözcügüü, 'Delport' ve 'Disport' sözcüklerinin kısaltılmış şeklidir. Oyun, oyalanma, işten uzaklaşma anlamlarını taşımaktadır (Balcıoğlu, 2003: 128). Spor kavramı 14. yüzyılda, İngiltere'de başlayan ulusallaşma hareketiyle ortaya çıktığ İngilizleştirilmesi amacıyla başındaki ekler atılınca 'disport', 'desport' biçimindeki kullanımlardan geriye 'sport' kalmıştır. Bir görüşe göre de spor sözcüğü günlük dile, Akdenizli denizcilerin limanda (port) geçirdikleri keyifli yaşantıyı denizdeki güçlüklerle dolu yaşamlarının karşıtı olarak anlatmak için argo niteliğinde kullanmalarıyla girmiştir. Spor, İspanyolca 'de porte' (limanda olmak) demektir. 14. yüzyılda gemiler uzun seferlerden sonra limana yanaştığında, yükler boşaltılırken denizcilerin limanda çeşitli oyunlar oynadıklarıyla ilgili bilgiler bulunmaktadır. Bu oyunların eğlendirici ve rahatlatıcı nitelikte olmakla birlikte, sertlikler barındırdığı kaydedilmektedir (Özsoy, 2011: 89-90). Yüzyıllar boyunca insanlığın vazgeçemediği bir uğraş olan spor, günümüzdeki anlamıyla, tek başına toplu veya takım halinde yapılan, kendine özgü kuralları, teknikleri olan, bedensel ve zihinsel yetilerin gelişmesini sağlayan, eğitici, eğlendirici uğraşı olarak da tanımlanabilir (Savaş, 1997: 304).

Spor, Orta Asya bozkırlarında göçebe olarak yaşayan Türkler arasında da revaçtaydı. Türkler yaratılışları icabı savaşçı ve mücadeleci bir topluluktur. Aynı zamanda gelenek, görenek, örf ve adetlerine bağlı, bunlardan taviz vermeyen insanlar olarak bilinen Türkler, sportif faaliyette de kendilerini gösterdiler ve başarı sağladılar. Vahşi sürüler halinde gezen atları evcilleştirerek harp ve spor vasıtası olarak kullandılar. At yarışları: Kaçma-kovalama, at üzerinde ok atma, mızrak kullanma, Gök-börü, Kız-börü ve Beyge oyunları Türklerin at üzerindeki oyunlarıdır. Türkler ok kullanmakta çok mahirdiler. Onlar için ok ve yay, at kadar kıymetli sayılmıştır (Kurt, T. ve diğerleri, 2015: 9-27). 
Toplumların farklı şekilde yaşamlarına dâhil etikleri sporun, sağlıklı yaşamın vazgeçilmez bir parçası olmasının yanı sıra, insanları ve toplumları kaynaştırma ve yakınlaştırma gibi bir misyonu da vardır. Gelişmişlik ve geri kalmışlık farkı, sporda da kendisini ortaya koyar. Gelişmiş ülkeler genellikle sporun her dalıyla ilgilenmekte ve başarılı olmakta iken geri kalmış ülkeler ve sporcuları diğerlerine göre daha az maddi yatırım gerektiren spor dalları ile ilgilenmekte ve bu spor dallarında (atletizm gibi) başarı göstermektedirler.

Orta Asya'daki Türklerin ise başarı gösterdikleri spor dallarının başında güreş gelmektedir. Bunun yanında koşular, cirit, çöğen de yaptıkları başlıca spor dallarıydı. Türkler, düğünlerde, bayramlarda, şenliklerde çeşitli spor gösterileri yaparlardı.

Türkiye'de modern spora Selim Sırrı Tarcan öncülük etmiştir. (Oğuzkan, 1997: 18) Ayrıca 1903'te kurulan Beşiktaş Osmanlı Jimnastik Kulübü, 1905'te kurulan Galatasaray ile 1907'de kurulan Fenerbahçe, Türkiye'deki ilk spor ve futbol kulüpleri oldular. Cumhuriyetten sonra Türkiye'de hızla gelişen spor, büyük bir sporcu ve izleyici kitlesini içine aldı (Çevrimiçi, 2014, 10 Mart).

Nitelikleri itibariyle spor, sadece boş zaman faaliyeti değildir. Spor' u eğitim, fizyoloji, psikoloji, sosyoloji, sağlık, gençlik, çalışma hayatı, sosyal güvenlik gibi sahalardan veya konulardan ayrı düşünebilmek mümkün değildir (Erkal, M., Güven, Ö. ve Ayan, D., 1998: 189). Yaşamın birçok alanında yer alan ve çeşitli şekillerde bireye katkı sunan sporun ayrıca uluslararası alanda bir toplumun kültürünün tanitılabileceği çok yaygın bir propaganda ve reklam aracı olduğunu da unutmamak gerekir (DPT, 2000: 5). Öte yandan spor, elde edilen gelirler bakımından oldukça büyük bir ekonomiyi teşkil etmektedir. Bu özelliklerinden dolayı sporun kapsadığı alan da oldukça genişlemektedir.

\section{Kavram Olarak Siyaset ve İktidar Olma}

Kavram olarak zaman zaman politikayla eş anlamlı kullanılan siyaset, farklı şekillerde tanımlanmaktadır. 'Yaşayan insanlar arasında bir mücadele ve çatışma hali' (Akyüz, 2009: 95), şeklinde tanımlanabildiği gibi, 'çatışmaları çözüme kavuşturma süreci' olarak ta açıklanabilir. Nasıl tanımlanırsa tanımlansın siyasetin esas amacı kendine özgü dil, üslup ve argümanlar ile insanları etkileyerek, onları kendi saflarına dâhil etmektir.

Varlığını ve devamlılığını halkın teveccühüne borçlu olan siyaset kurumu ve siyasiler, toplumun gerçeklerini görmezden gelemeyeceklerinin bilincindedirler. $\mathrm{Bu}$ yüzden toplumun beklentileri, talepleri ve ihtiyaçlarının yanı sıra, halkın ilgi gösterdiği ve değer verdiği başka olgulardan da bağımsız hareket edememektedirler.

Siyaset kurumu iktidara gelmek ve bu durumu devam ettirmek üzerine kurulmuş yapılar, siyasiler de bu uğurda mücadele eden aktörlerdir. İkna etmekten başka yönetim şeklinin kabul görmeyeceği günümüz toplumlarında, siyasiler iktidar olmada ve iktidarlarını sürdürmede birçok farklı yol, yöntem ve teknikler denenmiş ve denemeye de devam etmektedirler. 
Siyasilerin iktidar mücadelesinde sonuca ulaşmak adına -dönemin gerektirdiğiher imkânı değerlendirmek, her argümanı kullanmak arzusunda olmuşlardır. Bu imkânlardan biri de birçok insanın farklı şekilde ilgilendiği spor olaylarıdır. Üstelik spor yüzyıllardır kitlelerin yaşamlarında var olmuş bir olgudur. Toplumun spora olan ilgisi ile siyasilerin bu ilgiyi kendi çıkarları için kullanarak taraftar toplama çalışmaları ve ayrıca bu uğurda ortaya koydukları çabalar siyasetle sporun iç içe olmasına sebep olmuştur.

\section{Siyaset ve Sporun İlişkisi}

Kimi zaman kitlelerin afyonu olarak nitelendirilen, kimi zaman kişilerin ruh ve beden sağlığını güvence altına alarak günlük yaşamın gerginliğini azaltan bir unsur olarak değerlendirilen spor, Ludwig John tarafından 'yurtsever, hiyerarşik, ve otoriter bir devlet eliyle ulusal birliği örgütleyen bir eğitim aracıdır' şeklinde tanımlanmıştır. Sporun kitlelerin afyonu olduğunu destekleyen, Francisco Franco'nun, Bernabeau stadyumunu kastederek 'bana 150 bin kişilik uyku tulumu yapın' ifadesi ile, Antonio Salazar'in 'Portekiz'i kırk yıl Fiesta (şölen), Fadima (örgütlü din), ve Futbol (3 F) ile yönettim' sözleridir (Sert, 2000: 31). Bu ifadelerden, sporun iktidarlar ile kitleler arasındaki ilişkisi hakkında çıkarımlarda bulunmak mümkündür.

Toplumda, ekonomik, kültürel ve diğer yaşam alanlarında örgüsel bir ilişki içinde bulunan güç odakları (iktidarlar), insan bedeni üzerinde -çoğu zaman birbirleriyle iş birliği yaparak- uyguladığı politikalarla adeta bedenleri alt üst etmektedirler. Bu politikaların neler olduğunu, günlük yaşamımızda sportif ve kültürel seçimlerimizin yönlendirilmesinde, tüketim alışkanlıklarımızın şekillenmesinde, moda anlayışının oluşturulmasında, ekonomide vb. alanlarda gözlemlemek mümkündür. (Sert, 2000: 18) Pierre Bourdieu da, insanların spor uygulamalarını seçmesinin arkasında siyasal spor felsefesinin olduğunu ileri sürerek, bedenin ticarileştirilerek bir tüketim nesnesine dönüştürüldüğünü savunmuştur (Bourdieu, 1997: 164).

İçinde bulundukları rejimin türü ne olursa olsun, siyasi partilerin ve kurdukları hükumetlerin spor politikaları olmuştur ve sporla siyasiler bir etkileşim içerisinde bulunmuşlardır. Spor ve siyasetin etkileşimi spor kulüpleri ve dernekleri, profesyonel sporcular, spor donanımı üreticileri, spor olaylarını organize edenler, spor medyası, sponsorlar, reklamcılar, acenteler, modacılar vb. aracılığıyla çeşitli düzeylerde olmuştur.

Spor, öncelikle siyasal ideoloji tarafından kendi iktidarının meşruiyeti için kullanılmış ve bir nevi propaganda aracı haline getirilmiştir. Bunun en uç örnekleri, Hitler Almanya'sı, Franco İspanya'sı ve Salazar'ın Portekiz'idir. Ayrica spor, bilhassa da futbol, Latin Amerika ülkelerinde iktidarı ele geçiren askeri idarelerin sıkça kullandıkları bir manipülasyon alanıdır. (Talimciler, 2010: 45)

Günlük yaşamın önemli unsurlarından biri olarak kabul edilen sporun siyasetle ilişkisi yıllar öncesine dayanır. İlk büyük siyasi etkileşim 1936 Olimpiyatlarında Nazi Almanya rejiminin, Berlin Olimpiyatlarını mümkün olan tüm şekillerde bir 
propaganda aracı olarak kullanmış olmasıdır. Bu da Hitler Rejiminin gerekçelendirilip reklamının yapılması ile gerçekleşmiştir. Politik meşruluğun yaratılması sırasında spor, doğal bir araç olarak kullanılmıştır (Algün G. ve Sunay H., 2010: 98). Polonya, Almanya gibi ülkeler spor olaylarını anayasal güvence altına almış, sporu bireysel hak olarak tanımlamıştır. Bunun yanı sıra SSCB Komünist Partisi en önemli görevlerden biri saydığ1 sporu ve spor eğitimini parti programına almıştır (Sert, 2000: 49). Sosyalist blok döneminde Doğu Almanya'da ve Sovyetler Birliği'nde, devlet kurumlarının sporla ilgili izleyecekleri eylem programları hazırlanmış ve uygulanmıştır (Talimciler, 2010: 46).

Pek çok milletten oluşan ve farklı dillerin konuşulduğu İspanya'da ise iktidarların özellikle futbol üzerinden uyguladıkları politikalar oldukça ilgi çekicidir. İspanya'nın dünyaca ünlü iki takımı Real Madrid ile Barcelona'nın, futbolun öteside mücadelesi adeta bir kimlik, bir iktidar mücadelesine dönüşmüştür. Barcelona yandaşlarının (Katalanların) Real Madrid'i rakipten öte düşman olarak görmeleri; onu merkezi iktidarla özdeşleştirmelerinden kaynaklanmaktadır. Real Madrid'in Avrupa kupalarındaki başarıları, merkezi hükumetin gücü gibi lanse edilmiş ve merkezi iktidarı simgelemiştir. İspanya'da faşist olarak nitelendirilebilecek Franco'nun 1930'lardan 1980'lere kadar iktidarını sürdürmesinde Real Madrid'in rolü büyüktür. Futbolun kitleleri kuşatan gücünün bilincinde olan Franco, bunu çok iyi kullanmıştır. Dünyanın çeşitli yerlerinden en iyi futbolcuları transfer ederek Real Madrid'i dünya çapında yenilmez bir takım haline getirerek, İspanyol halkının tepkilerini uzun yıllar kontrol edebilmiştir (Sert, 2000: 75-76).

Faşistlerin Cumhuriyetçileri yendiği 1930'ların sonunda futbol, Franco'nun Falanjist partisinin denetimi altına girmiştir. Sporun örgütlenmesinden sorumlu General Mascardo'nun 'siyasal hedeflerimizi gerçekleştirmede spor ve futbol en önemli araçlarımızdan biridir' (Sert, 2000: 76) ifadesi rejimin ve siyasal iktidarın sporla ilişkisini göstermesi açısından önemlidir. Buna benzer bir uygulamayı Cumhuriyetçiler Madrid kentinin ikinci büyük takımı Atletico Madrid'le yaptılar. Harcanan paralarla Atletico güçlendi. Artık futbol, olayın görünen yüzü olmuştu. Mücadele faşizm ile demokrasinin futbol alanındaki karşılaşmasıydı.

\section{Türkiye' de Siyaset Spor İlişkisi}

Türkiye'de, gerek Osmanlı döneminde gerekse Cumhuriyet döneminde, sporun ülkede yaşanan siyasal ve ekonomik gelişmelerden etkilendiği görülmektedir. Tanzimat fermanı ile Osmanlı'nın toplumsal ve siyasi yaşamda yönünü batıya dönmesi sporda da kendini göstermiştir. Bu bağlamda güreş gibi geleneksel ve bireysel oyunların yerini, örgütlenmeyi gerektiren takım oyunları almıştır. Sonrasında ise spor, başta okullar olmak üzere çeşitli şekilde yaşamın içinde daha fazla yer edinmeye başlamıştır. Üstelik sporun sosyal yaşama yayılmasına iktidarlar öncülük etmişlerdir. İlerleyen yıllarda özellikle de Cumhuriyet sonrası dönemde devletin ve siyasi otoritenin sporla olan ilişkisi artarak devam etmiştir.

Meşrutiyetin ilanından sonra, fırka ve partiler kurdukları spor kulüpleri aracılığıyla gençlikle yakından ilgilenmişlerdir. İzmir'de 1912 yılında kurulan 
Karşıyaka Kulübü Müdafaa-i Milliye isimli bir siyasi teşekkül tarafından desteklenmişti. Bu duruma ilgisiz kalmayan İttihat ve Terakki Fırkası da Celal Bayar öncülüğünde İzmir'in ileri gelen idareci ve sporcularıyla anlaşarak Altay kulübünü kurmuşlardır. İzmir'in siyasete karışan iki kulübüne karşılık İstanbul'da da daha önce Progres adıyla kurulan bir kulübün ismi Altınordu olarak değiştirilmiş, Sadrazam Talat Paşa ve bazı mebuslar yönetim kurulu üyeliğine getirilerek kulübe büyük yardımlar yapılmıştır. Hatta bu kulübün sporcularına vatani görevlerini İstanbul'da yapma imkânı da sağlanmıştı (Ertuğ, 1997: 35).

Devlet, her Türk vatandaşının beden ve ruh sağlı̆̆ını geliştirmek amacıyla sportif hizmet ve faaliyetleri yürütmek, geliştirmek ve yurt sathına yaygınlaştırmak görevini merkezi idareye bağlı GSGM vasıtasıyla üstlenmiştir (Cankalp, 2002: 3-14). Devletin bu sorumluluğu bizzat üstlenmiş olması, sporun bir devlet politikası olarak ele alındığını göstermektedir.

Cumhuriyet sonrası dönemdeki örgütlenmelerde ise devletin spordaki etkinliği iyiden iyiye hissedilmiştir. Sporun ve sporcunun devlete bağlanması prensibiyle dönemin sporcuları dönemin partisi olan Cumhuriyet Halk Partisi'ne (CHP) üye yapılmıştır. Hatta 1936 Berlin Olimpiyat Oyunlarına katılan Türk Sporcular göğüslerinde ay-yıldızın yanında Cumhuriyet Halk Partisi'nin sembolü olan altı oklu logoyu da taşımışlardır (Talimciler, 2010: 48). Böylece elde edilecek başarılardan siyasiler kendilerine pay çıkarmayı düşünmüşlerdir.

Aynı dönemlerde CHP'nin yan örgütü olan Halkevleri aracılığıyla sporun üzerinde hâkimiyet oluşturulmaya çalışılmış, CHP il başkanları, spor bölgesi başkanlıklarına atanmış, başbakan spora doğrudan müdahale eder pozisyonda bulunmuştur. (Sert, 2000: 110).

1900'lü yılların ikinci yarısından itibaren PTT, DSİ, Köy Hizmetleri, gibi doğrudan iktidarlar tarafından kurulan kulüplerin yanında, Çaykur Rizespor, TKI Linyitspor, Batman Petrol Spor, MKE Ankaragücü vb. kulüpler de yine kamu eliyle kurulmuş ya da desteklenmiştir. Bununla birlikte yerel yöneticiler de belediyelerin iştirakiyle belediye spor kulüpleri kurarak sporun içerisinde yer almayı amaçlamışlardır.

Siyasi iktidarların spora karıştıkları kadar destek olmadıkları alınan sonuçlarla ortadaydı. Siyasilerin spora olan destekleri -özellikle altyapı konusunda- ideal seviyede olmadığından elde edilen başarı da sınırlıydı ve beklentileri tam manasıyla karşılamıyordu. Özellikle uluslararası organizasyonlarda elde edilen sonuçlar tatmin edici değildi. Bu eksikliği gidermek maksadıyla Türkiye dışında yaşayan ve alanlarında başarılı olan sporcuları Türkiye adına yarışmalara katılmaya ikna etme yoluna gidilmişti. Bu bağlamda örtülü ödenekten Bulgar hükumetine 1 milyon dolar ödenerek Türk vatandaşı yapılan ve Türkiye adına yarışması sağlanan dünya halter şampiyonu Naim Süleymanov (Naim Süleymanoğlu) bu çabalara iyi bir örnektir (Sert, 2000: 123). Süleymanoğlu'nun elde ettiği şampiyonluklardan hem uluslararası arenada 'güçlü Türkiye imajı, hem de iç politikada güçlü hükumet/iktidar imajıla popülarite sağlanılması amaçlanmıştır. Atletizmde zirvede bulunan isimlerden Elvan 
Abeylegesse' de Türkiye' de yetişmeyen ancak Türkiye adına yarışan sporculardandır. Son yıllarda benzer şekilde masa tenisi, judo, boks, futbol, halter, vb. dallarda devşirme sporcular Türkiye adına yarışmalara katılmaktadırlar.

Son dönemlerin en ilginç olaylarından biri de 2020 Olimpiyat oyunlarının Türkiye'de yapılması için Türk hükumetinin olağanüstü çaba göstermesiydi. Büyük siyasi kazanç sağlaması düşünülen 2020 Olimpiyatlarının Türkiye'de yapılması hususunda Ak Parti hükumeti yoğun çaba harcamış, olimpiyatların Türkiye'de yapılması milli mesele gibi gösterilmişti. Aslında 2020 olimpiyatları Ak Parti'nin belirlediği 'Hedef 2023' vizyonuyla örtüşüyor ve iktidara büyük güç sağlayacağ1 düşünülüyordu. Bu yüzden Ak Parti hükumeti de 2020 olimpiyatlarının Türkiye'de yapılması için yoğun çaba göstermişti. Öte yandan muhalefetteki siyasiler de olimpiyatların Türkiye'de yapılmasına karşı çıkarak ülkeye getireceği maddi yüke değiniyor, olimpiyatları Ak Partinin siyasi çıkar elde etmek maksadıyla kullanacağını düşünüyorlardı.

Bütün bu çaba ve girişimler, siyasilerin özde olmasa da sözde sporu destekledikleri ve tüm dünyada olduğu gibi Türkiye'de de siyasilerin spordan bir kazanç elde etme uğrunda çaba gösterdiklerinin kanıtı niteliğindedir.

\section{Sonuç}

Başlangıç olarak insanlı̆̆ın bilinebilen tarihine kadar uzanabilen spor olgusu, özellikle son iki yüz yıldır büyük kitlelerin ilgisini -giderek artan oranda- çekmektedir. Toplumsal yaşamda meydana gelen değişim ve dönüşümlerden hareketle, sporun basit bir olgu olmadığ1 ve günümüzde bir yaşam biçimine dönüştüğü sonucunu çıkarmak mümkündür. Sporun bireye fiziki katkısının yanı sıra başkalarıyla olan ilişkilerde de saygı, sevgi, anlayış, hoşgörü, sevinç, üzüntü paylaşımları vb. değerlerin oluşturulmasında ve yerleşmesinde önemli etkisi vardır. Spor aracılığıyla edinilen bu değerler toplumsal uyum mekanizmalarını harekete geçireceği düşünüldüğünde, siyasilerin politikalarını benimsetme ve yerleştirme uğraşında sporun oynayacağı rolün ne denli önemli olduğu ortaya çıkmaktadır.

Birçok dünya ülkesinde olduğu gibi Türkiye'de de iktidarlar genel manada sporun, özel de de futbolun kalabalık kitlesinden ürkmüşlerdir. Bu heyecanlı kalabalığın farklı şekillerde uygulanan yasaklarla kontrol altına alınamayacağı kabul edilmiş ve onları kazanmanın tek yolunun heyecanlarına ortak olmaktan geçtiği anlaşılmıştır.

$\mathrm{Bu}$ anlayıştan hareketle, hemen her dönemde çoğu ülkede iktidarlar spor olaylarının içinde yer almayı bir politika olarak benimsemişlerdir. Hatta sporun tek hâkimi konumunda bulunmayı arzulamışlardır. Bu yüzden spor alanında iktidarların, kişilerin spora ve spor olaylarına yönelmesinde hatta spor zevkinin oluşmasında belirleyici rol oynadıkları ve siyasilerle spor arasında yakın bir ilişki olduğu açıkça görülmektedir. Bu ilişkinin oluşmasında siyasilerin çıkarları ve onlar tarafından oluşturulan felsefenin etkin olduğu anlaşılmaktadır. 
İnsanların gündelik yaşamlarında, gelecekle ilgili düşüncelerinde, önemli bir yer tutan spor, iktidarların güçlerini artırmaya yönelik politikalarını oluşturmalarında da başat bir konuma sahiptir. Bireyler için iyi ve uzun yaşama imkânı sunan spor olgusu, ülkelerin güç gösterisinde de önemli yer tutması sebebiyle iktidarlara geniş hareket alanı sağlamıştır. Spor olaylarından elde edilecek başarının ülke içinde ve uluslararası platformda sağlayacağı olumlu imaj ve kazançlar, iktidarların uzun ömürlü olmasını destekleyeceği düşüncesiyle spor elde tutulmaya çalışılmıştır.

Bu uğurda her türlü çabanın gösterildiği açıktır. Sportif çalışmaların parti programlarının ilk sırasında yer almasından, yurtdışından sporcu getirtilmesine kadar, siyasiler tarafından çok farklı çalışmalar yapılmıştır. 2000'li yıllarda ise özellikle genel seçimler öncesi siyasiler futbol kulüplerine yardım için yarışa girdikleri, mekânlardan, milletvekillerine hatta Parti İl Başkanlarına kadar birçok siyasetçi aday olduğu ilin futbol kulüplerine yardımlarıyla dikkati çekiyordu. Seçim dönemleri öncesinde kulüpler istekte, siyasiler de vaatte sinır tanımıyordu. Siyaset ve futbol yine kol kola girmişti (Yedigün, 2013).

Hatta Türkiye'de 1997-1998 sezonunda doğu ve güneydoğu takımlarının birinci ligden ikinci lige düşmesi üzerine bölge milletvekilleri harekete geçmiş ve sadece bir sezona özgü ligden liglerden küme düşmenin kaldırılması için bir yasa teklifi hazırlamış ve meclise sunmuşlardı (Sert, 2000: 43).

Siyasiler spor olgusunun nimetlerinden yararlanmak adına ulusal ve uluslararası düzeyde başarılar elde etmiş isimleri milletvekili adayı yaparak ulusal manada destek bulmayı amaçlamışlardır. Ayrıca katıldıkları her mitingde o bölgenin ya da kentin takımlarına ait kaşkol ya da formalarla meydanlarda konuşmayı uygun görmüşlerdir.

Sonuçta siyasiler destekçilerini artırmak adına sporun nimetlerinden her fırsatta faydalanmayı düşünmüş, bu doğrultuda ellerinden gelini yapmışlar ve yapmaya da devam etmektedirler.

\section{KAYNAKÇA}

Yaylagül, L. ( 2010). Kitle İletişim Kuramları Egemen ve Eleştirel Yaklaşımlar. Ankara: Dipnot Yayınları.

Balcığlu, İ. (2003). Sporun Sosyolojisi ve Psikolojisi. İstanbul: Bilge Yayınları.

Çevrimiçi, (2014, 10 Mart). Spor. http://spor.nedir.com/\#ixzz2vYsJqSCz, Erişim tarihi: 10 Mart 2014.

Özsoy, S. (2011, Mart). Spor Gazetelerinin Başlıklarında Militarist ve Şiddet İçerikli Metaforlar, Gümüşhane Üniversitesi İletişim Fakültesi Elektronik Dergisi, Sayı: 1.

Savaş, İ. (1997). Spor Genel Kültürü, İstanbul: İnkılâp Kitabevi.

Kurt, T., Kılıç, M., Kılıç, M. N. ve Özbayraktar, F. (2015). Türk Spor Tarihi, Ankara: Milli Eğitim Devlet Kitapları, 6. Bask1.

Oğuzkan, A. F. (1997). S. Sırrı Tarcan Yaşamı ve Hizmetleri. Ankara: Türk Eğitim Derneği Yayınları, Eğitimcilerimizi Anma ve Tanıtma Dizisi: 5. 
Akyüz, Ü. (2009, Ocak, Şubat, Mart, Nisan), Siyaset ve Ahlak, Yasama Dergisi, Say1: 11, ss.93-129.

Erkal, M., Güven, Ö. ve Ayan, D. (1998). Sosyolojik Açıdan Spor (3. Basım). İstanbul: Der Yayınları.

DPT. (2000). Beden Ĕ̆itimi, Spor ve İstanbul Olimpiyatları. Ankara: Özel İhtisas Komisyonu Raporu.

Sert, M. (2000). Gol Atan Galip, Futbola Sosyolojik Bir Bakış. İstanbul: Bağlam Yayınları.

Bourdieu, P. (1997). Toplumbilim Sorunları. Hülya Tufan (Çev.). İstanbul: Kesit Yayıncılık.

Algün G. ve Sunay H. (2010, Mart). Uluslararası İlişkiler ve Spor. Spormetre Beden Ĕ̆itimi ve Spor Bilimleri Dergisi, , Sayı: VIII.

Cankalp, M. (2002). Sporda Yönetim ve Organizasyon. Ankara: Nobel Yayın-Dağıtım.

Talimciler, A. (2010). Sporun Sosyolojisi, Sosyolojinin Sporu. İstanbul: Bağlam Yayıncılık.

Ertuğ, A.R., (1997). Türkiye Futbol Tarihi 1890-1923. Ankara: Ankara Bölge Müdürlüğü Yayını. 